\title{
Establishment of Standard Reference Environment for Photovoltaic Nominal Operating Cell Temperature Testing with Dedicated Approach for Tropical Region
}

\author{
M.M.M. Hanifah ${ }^{1}$, H. Zainuddin ${ }^{2}$, M.Z. Hussin ${ }^{3}$ \\ ${ }^{1,2}$ Faculty of Applied Sciences, Universiti Teknologi MARA, 40450 Shah Alam, Selangor. Malaysia \\ ${ }^{3}$ Faculty of Electrical Engineering, Universiti Teknologi Mara Johor, Kampus Pasir Gudang, 81750 Masai, \\ Johor. Malaysia
}

\begin{abstract}
Article Info
Article history:

Received May 1, 2018

Revised Jun 30, 2018

Accepted Jul 15, 2018

\section{Keywords:}

Photovoltaic

Standard Reference

Environment

Nominal Operating Cell

Temperature

Tropical Region

ABSTRACT

This paper presents the establishment of Standard Reference Environment (SRE) for photovoltaic (PV) Nominal Operating Cell Temperature (NOCT) testing in Malaysia representing one of the countries that lies in tropical region. From a field testing conducted, 12-months data of six parameters namely solar irradiance (SI), ambient temperature (AT), relative humidity $(\mathrm{RH})$, wind speed (WS), wind direction (WD), module temperature (MT) and open circuit voltage were analysed to determine the median SI and the median AT. From the analysis, the median SI and the median AT are 228 $\mathrm{W} / \mathrm{m}^{2}$ and $30{ }^{\circ} \mathrm{C}$ respectively. However, these results show that the current approach in determining SRE using median ambient parameters is not suitable for tropical Malaysia based on the percentage error of approximately $30 \%$. Due to this, the proposed approach applied in this study is determining the corresponding AT of the same SI $\left(800 \mathrm{~W} / \mathrm{m}^{2}\right)$ used in present SRE of international standard. Thus, the new proposed SI and AT for SRE in this study are $800 \mathrm{~W} / \mathrm{m}^{2}$ and $31^{\circ} \mathrm{C}$ respectively. The SRE found in this study is determined using dedicated approach to suit tropical climate in deriving a more accurate NOCT for tropical region.
\end{abstract}

Copyright () 2018 Institute of Advanced Engineering and Science. All rights reserved.

Corresponding Author:

H. Zainuddin,

Faculty of Applied Sciences,

Universiti Teknologi MARA,

40450 Shah Alam, Selangor. Malaysia.

Email: zainuddinhedzlin@gmail.com

\section{INTRODUCTION}

Rapid growth in PV system installations in the world has created significant impact on the momentum including tropical regions. Malaysia is a country that lies in the range of approximately 1 to 7 degrees north of latitude of equatorial line and grouped under tropical region countries [1]. There are a few policies and incentives implemented by Government of Malaysia including 'National Renewable Energy Policy and Action Plan, 2009', 'Renewable Energy Act 2011', 'Feed-In-Tariff' (FiT) scheme and 'Large Scale Solar Photovoltaic Plant' (LSS) [2]. The PV system installation has reached 362.34 MW of capacity under FiT scheme as reported by Sustainable Energy Development Authority Malaysia excluding the other incentives [2].

The tremendous momentum has created an urgency of setting up PV testing facility for many PV certifications such as IEC61215 [3] and IEC61646 [4] in tropical region [5]-[7]. Testing under control environment such as lab base is not a big issue. Nevertheless, the NOCT testing requires outdoor PV testing facility instead of lab base. The outdoor testing facility is of significant worries because it must represent the 
real outdoor environment of the location where the PV system will be installed as discussed in the preliminary study [7].

Nominal Operating Cell Temperature (NOCT) testing procedure is an outdoor testing procedure used in IEC 61215 and IEC 61646. The NOCT values obtained from the testing will be used by system designers as a guide of the operating temperature of the PV module in the field [3]. The NOCT values are determined based on Standard Reference Environment (SRE) which covers PV module tilt angle of 45 degrees from horizontal, irradiance (SI) of $800 \mathrm{~W} / \mathrm{m}^{2}$, ambient temperature (AT) of $20^{\circ} \mathrm{C}$, wind speed (WS) of $1 \mathrm{~m} / \mathrm{s}$ and PV module at open circuit condition [3], [4], [8].

In procedure section of NOCT testing under 10.5.3.4, stated that data of SI has to be greater than $400 \mathrm{~W} / \mathrm{m}^{2}$ [3]. Tropical regions are areas of having fast-changing SI with plenty of clouds, high AT and high relative humidity $(\mathrm{RH})$ [9], [10]. Based on the preliminary study conducted in evaluating the SRE for NOCT testing in Malaysia, the median SI was $300 \mathrm{~W} / \mathrm{m}^{2}$ [7]. This median SI has given an insight that this value will not work with the existing NOCT procedure. However, it is very important to follow as close as possible with the existing NOCT procedure for further comparison in the future. Due to this argument, a study will be conducted in establishing an SRE for NOCT testing with dedicated approach for tropical region. In order to achieve this, median values of ambient parameters of SRE will be determined and evaluated.

\section{RESEARCH METHOD}

The methodology applied in this study was aiming to establish an SRE for NOCT testing that represent tropical Malaysia condition by following as close as possible to the present international standards procedures and mechanism [3], [4]. In order to do this, the methodology has to be of tropical approach consisting field testing, sufficient data collection and analytical method.

The field testing conducted is referring to the outdoor module testing of NOCT that complies with the requirement of international standards in the aspects of experimental setup, data logging and sensors accuracy as reported in the preliminary study [7]. There is no changes made in terms of these three aspects as compared to the preliminary study reported earlier except that the data collection has been extended for another six months [7]. In other words, the amount of data has increased by $50 \%$ and the data will represent a climate profile for each month in a year. The addition of another six months data of five minutes logging interval will form a complete one-year cycle of data collection represented by 12 months of February 2017 until January 2018.

The experimental setup for NOCT testing of monocrystalline, polycrystalline and CIS thin film PV modules; was built and operated under Energy and Environment Field Lab (EEFL), Universiti Teknologi MARA (UiTM), Shah Alam (Lat: $3.07^{\circ} \mathrm{N}$, Long: $101.49^{\circ} \mathrm{E}$ ). The NOCT testing setup as shown in Figure 1 was conducted in tropical Malaysia. The chosen tilt angle was $5^{\circ}$, which is an optimum tilt angle for optimum absorption of solar irradiance and natural cleaning by rain water as observed throughout the study [11].

Beside field testing, the analytical method applied were divided into four consecutive segments: Segment 1 was one-year statistical analysis of SI, AT, RH, WS, wind direction (WD), and module temperature (MT) of three PV cell technologies (MT_Mono, MT_Poly and MT_TF);. This segment aiming to give overall yearly picture of the real climate of tropical Malaysia with the corresponding MT at open circuit condition and determine the preliminary yearly median values of each parameters based on the data collection. Segment 2 was monthly statistical analysis of SI and AT, which are the two designated ambient parameters rated in SRE besides WS. It was done to magnify each month behaviour in terms of values of SI and AT and further confirm whether these parameters behave consistently with the yearly median values of SI and AT observed in Segment 1. Nevertheless, RH is another ambient parameter which the behaviour need to be looked into in the context of tropical Malaysia. This is because monthly RH is another corresponding parameter that need to be evaluated in this segment due to the hypothesis that it will have a relationship with the monthly trend of SI. Segment 3 will show the SI and AT monthly trend analysis in bar chart form. These will allow to evaluate whether the median AT and SI are suitable to be used as SRE for NOCT testing. The final segment was plotting graphs of temperature difference between MT and AT as a function of SI. A regression equation from this graph will be used to later finalised the SI and AT of the SRE that will suit tropical Malaysia. The percentage error was also calculated as performance indices of the chosen parameter for the proposed SRE. 

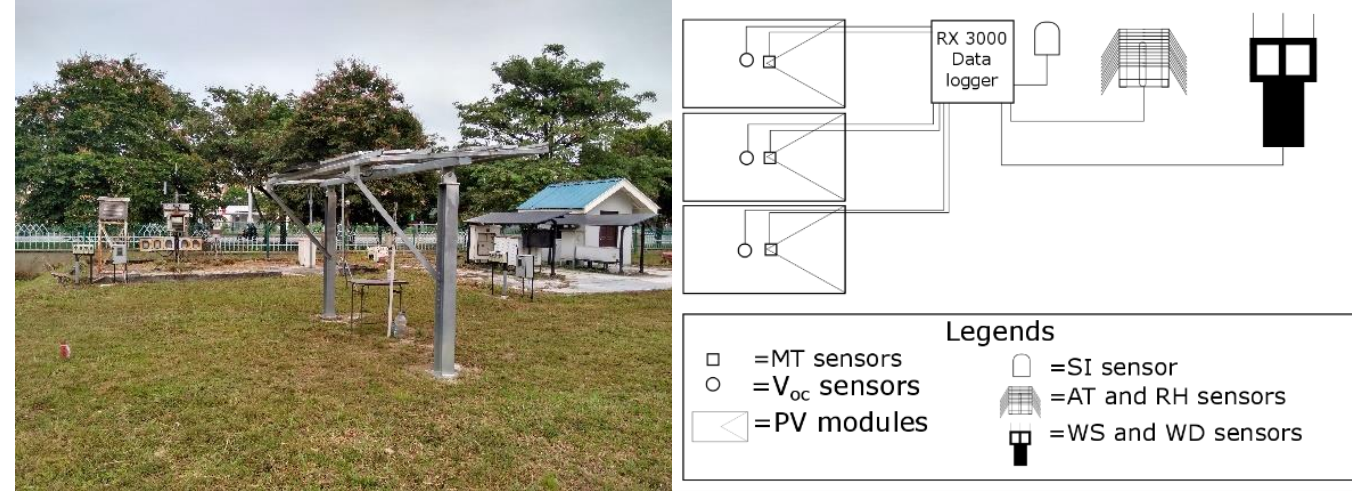

Figure 1. Experimental site view and NOCT Testing Setup Diagram

\section{RESULTS AND DISCUSSION}

\subsection{One-year statistical analysis of SI, AT, RH, WS, WD, MT_Mono, MT_Poly and MT_TF}

Statistical analysis was conducted on 12 months data consisting of approximately 48000 set of data. This analysis was conducted to come out with a year pattern of the climate profile in extension to the preliminary work conducted for six months of the same project reported earlier[7]. The statistical analysis tabulated in Table 1 comprises of eight parameters namely SI, AT, RH, WS, WD, MT_Mono, MT_Poly and MT_TF. The statistical indices encompass mean, standard error of mean, median, mode, standard deviation, skewness, standard error of skewness, range, minimum and maximum. Evaluating these parameters will elucidate the nature of the environment where NOCT testing procedures will be executed in this study especially in addressing SRE according to IEC61215. The mean values of four typical meteorological parameters of SI, AT, RH and WS in this study were $293 \mathrm{~W} / \mathrm{m}^{2}, 30.0{ }^{\circ} \mathrm{C}, 75 \%$ and $0.97 \mathrm{~m} / \mathrm{s}$. Apart from that, the mean WD was $164^{\circ}$, which was between east and south direction. The mean PV module temperature recorded for the three PV cell technologies namely monocrystalline, polycrystalline and thin film were $39.7^{\circ} \mathrm{C}, 40.2^{\circ} \mathrm{C}$ and $42.1^{\circ} \mathrm{C}$ respectively. These results give a significant indication to revise the SRE used in NOCT testing procedures for tropical region, which proven to have lower SI and higher AT with corresponding higher RH [7], [9]. However, further revision made in this study will be steered to be as close as possible to the present procedures as mentioned in international standard [3].

Table 1. One year statistical analysis for SI, AT, RH, WS, WD and MT for Mono, Poly and TF

\begin{tabular}{|c|c|c|c|c|c|c|c|c|}
\hline & SI & AT & RH & WS & WD & MT_Mono & MT_Poly & MT_TF \\
\hline Mean & 292.7516 & 30.0592 & 74.9511 & .9685 & 163.5992 & 39.6701 & 40.1921 & 42.0579 \\
\hline Median & 228.0000 & 30.3900 & 73.6000 & .8550 & 168.4400 & 38.6400 & 39.1500 & 41.1200 \\
\hline Mode & 7.00 & 31.33 & 100.00 & .13 & 1.53 & 24.80 & 25.28 & 24.75 \\
\hline Std. Deviation (SD) & 254.33291 & 2.93045 & 12.86119 & 60936 & 106.27913 & 10.64156 & 11.03260 & 12.42989 \\
\hline Skewness & .875 & -.245 & .162 & 1.251 & .056 & .314 & .324 & .294 \\
\hline $\begin{array}{l}\text { Std. Error of } \\
\text { Skewness (SEOS) }\end{array}$ & .011 & .011 & .011 & .011 & .011 & .011 & .011 & .011 \\
\hline Range & 1224.00 & 18.04 & 55.90 & 5.86 & 358.90 & 51.84 & 54.21 & 59.48 \\
\hline Minimum & 2.00 & 21.99 & 44.10 & .01 & .03 & 21.53 & 21.60 & 21.53 \\
\hline Maximum & 1226.00 & 40.03 & 100.00 & 5.87 & 358.93 & 73.37 & 75.81 & 81.01 \\
\hline
\end{tabular}

\subsection{Monthly Statistical Analysis of SI, AT and RH}

There are three ambient parameters involve from total five parameters as addressed in international standards. The three ambient parameters are SI, AT and WS. Based on the definition of SRE, the SI, AT and WS to be chosen as SRE in NOCT testing are the median values [8]. The statistical analysis as presented in Table 1 showed that the median for SI was $(228 \pm 10) \mathrm{W} / \mathrm{m}^{2}$, the median for AT was $(30.39 \pm 0.21){ }^{\circ} \mathrm{C}$ and the median for WS was $(0.86 \pm 0.11) \mathrm{m} / \mathrm{s}$. The WS median recorded in this study seems to have no issue to satisfy the requirement of international standards of $1 \mathrm{~m} / \mathrm{s}$. However, the median SI of $228 \mathrm{~W} / \mathrm{m}^{2}$ and AT of $30.39^{\circ} \mathrm{C}$ show significant different that need further evaluation. The corresponding median for the remaining ambient parameters of RH and WD were $(73.6 \pm 2.5) \%$ and $(168.44 \pm 2)^{\circ}$ respectively. In addressing NOCT testing's aim, which is to determine NOCT of the PV modules; the corresponding median of MT_Mono, MT_Poly and MT_TF were $38.64{ }^{\circ} \mathrm{C}, \quad 39.15^{\circ} \mathrm{C}$ and $41.12^{\circ} \mathrm{C}$ respectively. 
Since the results of a year analysis is an extension of the previous work of six months analysis, comparison was made to investigate the changes in the median values particularly the three ambient parameter of SI, AT and WS. From the previous six months analysis, the median SI was $(294 \pm 10) \mathrm{W} / \mathrm{m}^{2}$, meanwhile the median AT was $(31.36 \pm 0.21){ }^{\circ} \mathrm{C}[7]$. The differences occurred due to the addition of another six months data consisting from August 2017 to Jan 2018 in the one-year analysis. It is well known that in Peninsular of Malaysia specifically; November followed by December and January every year are rainy months, which is obviously indicated by the high values of RH based on Table 2. Referring to the RH monthly median, it was found that the month of January is getting the most rain with the mean RH of approximately $80 \%$ and the least corresponding irradiance of the mean SI of $243 \mathrm{~W} / \mathrm{m}^{2}$. The decrement in SI median was $29 \%$, meanwhile the decrement of AT median was $3 \%$. This is because the corresponding RH increment was $5 \%$.

Table 2. Monthly statistical analysis of SI, AT and RH

\begin{tabular}{|c|c|c|c|c|c|c|c|}
\hline Month & Parameter & Median & Mean & Max & Min & SEOS & SD \\
\hline \multirow[t]{3}{*}{ Jan } & SI & 183 & 243.55 & 1048 & 2 & 0.038 & 222.613 \\
\hline & AT & 28.79 & 28.6387 & 35.96 & 21.99 & 0.038 & 3.08604 \\
\hline & $\mathrm{RH}$ & 79.6 & 79.665 & 100 & 49.4 & 0.038 & 13.1627 \\
\hline \multirow[t]{3}{*}{ Feb } & SI & 261 & 335 & 1226 & 2 & 0.043 & 282.454 \\
\hline & $\mathrm{AT}$ & 30.8 & 30.18 & 35.9 & 23.59 & 0.043 & 2.58777 \\
\hline & $\mathrm{RH}$ & 66.6 & 69.469 & 98.8 & 44.1 & 0.430 & 13.766 \\
\hline \multirow[t]{3}{*}{ Mac } & SI & 244 & 322 & 1114 & 2 & 0.037 & 287.181 \\
\hline & AT & 30.6 & 30.3471 & 40.03 & 22.15 & 0.037 & 3.12118 \\
\hline & $\mathrm{RH}$ & 71.3 & 73.84 & 100 & 63 & 0.037 & 13.0173 \\
\hline \multirow[t]{3}{*}{ Apr } & SI & 259 & 322.05 & 1161 & 2 & 0.039 & 281.038 \\
\hline & $\mathrm{AT}$ & 30.88 & 30.4768 & 36.99 & 24.27 & 0.039 & 2.881631 \\
\hline & $\mathrm{RH}$ & 72.45 & 74.612 & 100 & 50.3 & 0.039 & 12.5636 \\
\hline \multirow[t]{3}{*}{ May } & SI & 216.5 & 282.68 & 1016 & 2 & 0.039 & 250.681 \\
\hline & $\mathrm{AT}$ & 30.77 & 30.49 & 35.93 & 23.52 & 0.039 & 2.72713 \\
\hline & $\mathrm{RH}$ & 75.6 & 76.592 & 100 & 51.8 & 0.039 & 11.6273 \\
\hline \multirow[t]{3}{*}{ Jun } & SI & 237 & 296.84 & 1056 & 2 & 0.041 & 249.726 \\
\hline & AT & 31 & 30.6594 & 36.93 & 23.16 & 0.041 & 2.76872 \\
\hline & $\mathrm{RH}$ & 71.4 & 72.888 & 98.2 & 45.2 & 0.041 & 12.1976 \\
\hline \multirow[t]{3}{*}{ Jul } & SI & 252 & 307.31 & 1002 & 2 & 0.037 & 244.197 \\
\hline & $\mathrm{AT}$ & 31.13 & 30.75 & 35.96 & 23.47 & 0.037 & 2.55904 \\
\hline & $\mathrm{RH}$ & 69.6 & 71.139 & 98.1 & 45.9 & 0.037 & 11.8439 \\
\hline \multirow[t]{3}{*}{ Aug } & SI & 234 & 286.55 & 1157 & 2 & 0.037 & 241.468 \\
\hline & $\mathrm{AT}$ & 30.24 & 29.9231 & 35.96 & 23.04 & 0.037 & 2.80605 \\
\hline & $\mathrm{RH}$ & 73 & 74.985 & 100 & 50.4 & 0.037 & 12.1727 \\
\hline \multirow[t]{3}{*}{ Sep } & SI & 233 & 295.02 & 1178 & 2 & 0.038 & 256.58 \\
\hline & $\mathrm{AT}$ & 30.155 & 29.9017 & 36.17 & 23.09 & 0.038 & 2.83773 \\
\hline & RH & 74.3 & 75.692 & 99.6 & 48.1 & 0.038 & 12.4697 \\
\hline \multirow[t]{3}{*}{ Oct } & SI & 236.5 & 308.11 & 1042 & 2 & 0.042 & 260.931 \\
\hline & $\mathrm{AT}$ & 30.8 & 30.4857 & 36.82 & 22.68 & 0.042 & 3.25306 \\
\hline & RH & 73.45 & 73.722 & 99.5 & 44.7 & 0.042 & 13.5539 \\
\hline \multirow[t]{3}{*}{ Nov } & SI & 183 & 246.64 & 1146 & 2 & 0.039 & 225.409 \\
\hline & AT & 28.99 & 28.9567 & 35.1 & 22.3 & 0.039 & 2.72069 \\
\hline & RH & 82.1 & 81.745 & 100 & 57.2 & 0.039 & 11.2807 \\
\hline \multirow[t]{3}{*}{ Dec } & SI & 221 & 276.48 & 997 & 2 & 0.039 & 231.166 \\
\hline & $\mathrm{AT}$ & 30.42 & 30.02 & 36.52 & 23.4 & 0.039 & 2.70172 \\
\hline & $\mathrm{RH}$ & 72.6 & 74.146 & 100 & 48.3 & 0.039 & 12.0854 \\
\hline
\end{tabular}

\subsection{Monthly Trends of SI and AT}

Figure 2 shows the monthly SI trends inclusive of median, mean, max and min values. The median SI for every single months was obviously lower than $400 \mathrm{~W} / \mathrm{m}^{2}$. These medians are considered as low irradiance level in international standards IEC61853-1 [12]. The monthly AT bar charts as shown in Figure 3 depicted high AT trend of approximately $30^{\circ} \mathrm{C}$ except for two months of slightly lower AT namely November and January. These AT values are significantly higher than $20^{\circ} \mathrm{C}$ as rated in IEC61215 [3]. There 
are few studies conducted in tropical region reported similar patterns of ambient parameters [9], [10]. From the macro picture of one-year analysis to more details monthly analysis of the ambient parameters discussed earlier, apparently there is a conflict in determining the SRE as the nature of SRE itself. In other words the median found in this study is supposed to be the SRE to represent the median environment of the test area representing tropical climate for NOCT testing [7], [8], [13]. It is well known that the rated SI is $800 \mathrm{~W} / \mathrm{m}^{2}$ and rated AT was $20{ }^{\circ} \mathrm{C}$ as stated in international standardsm [3]. Thus, making the median determined as above may not be used as SRE for NOCT testing.

The outcome of these median SI and AT leads to an alternative tropical approach in deriving to an accurate NOCT values. This approach follows the rated SI of $800 \mathrm{~W} / \mathrm{m}^{2}$, WS of $1 \mathrm{~m} / \mathrm{s}$ but proposed new AT rating for SRE to suit tropical region.

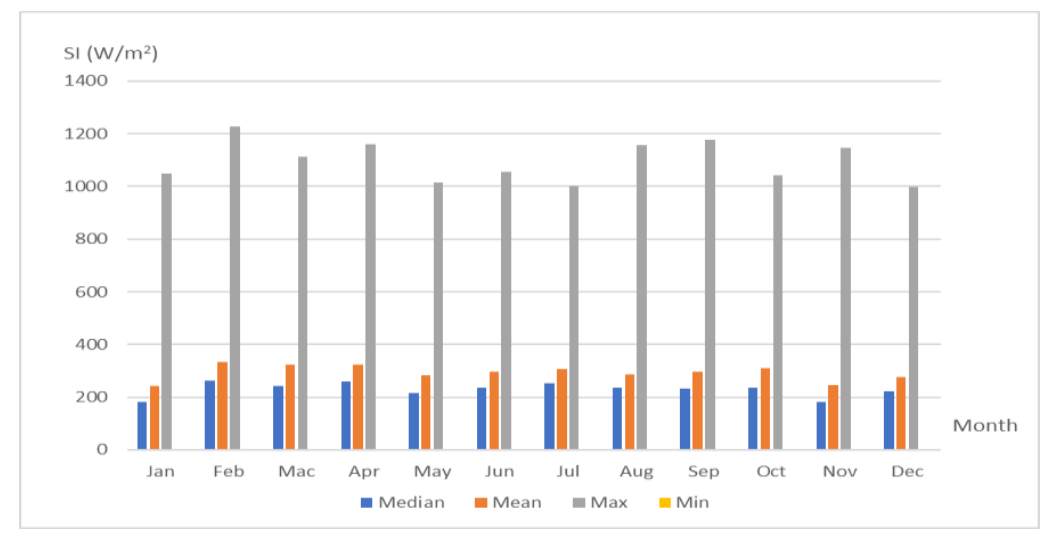

Figure 2. Monthly SI trend

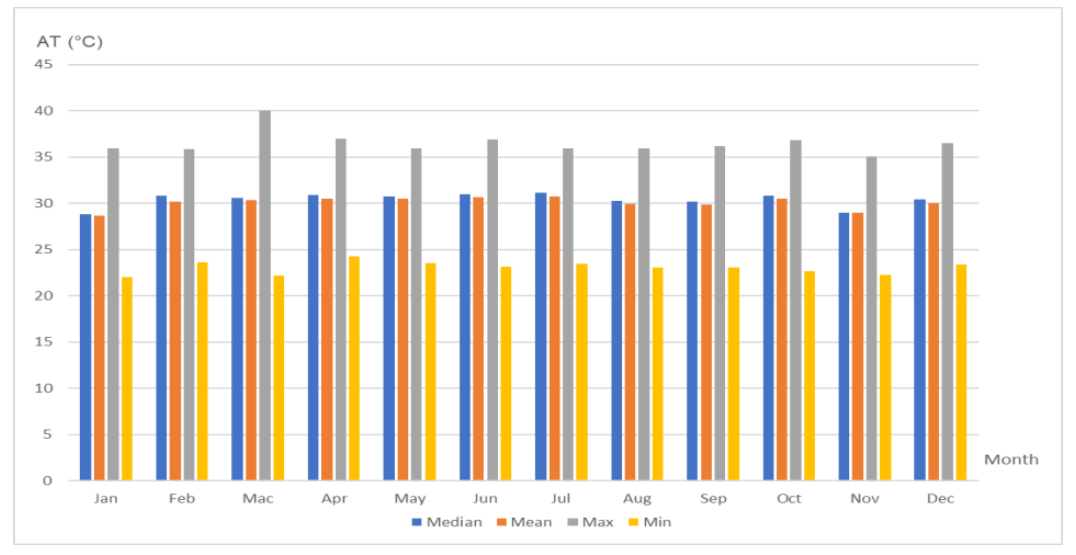

Figure 3. Monthly AT trend

\subsection{Delta $\mathrm{T}$ as function of $\mathrm{SI}$}

The new AT rating was determined by plotting graphs of temperature difference (delta T) between MT and AT, as a function of SI. Since this study involves three PV module technologies of monocrystalline, polycrystalline and thin film, three similar graphs were plotted as shown in Figure 4, Figure 5 and Figure 6 respectively. Each of these plotted graphs is represented by a linear equation that evolves from 5 minutes logging interval for a year duration. From each of these linear equation (Equation 1, Equation 2 and Equation 3), the corresponding AT at SI of $800 \mathrm{~W} / \mathrm{m}^{2}$ as rated in international standards was determined. The calculation in determining the AT values for each PV module technologies are shown:

Monocrystalline Linear Equation, $y=0.0269 x+1.7312$

Polycrystalline Linear Equation, $y=0.0285 x+1.7824$ 
Thin Film Linear Equation, $y=0.0329 x+2.3685$

Calculation in determining AT at SI of $800 \mathrm{~W} / \mathrm{m}^{2}$ :
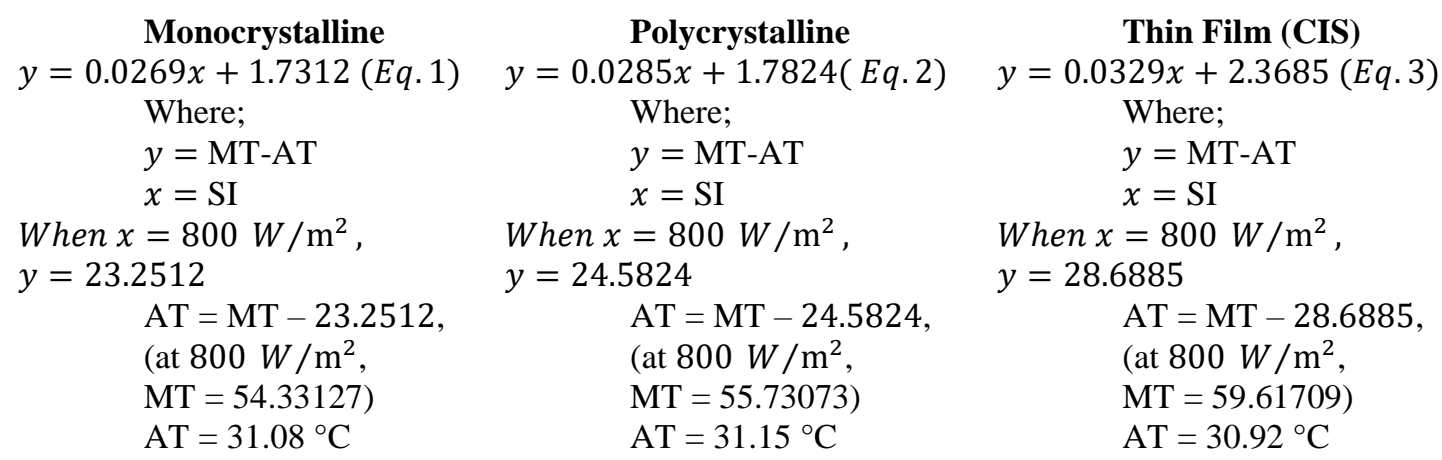

When $x=800 \mathrm{~W} / \mathrm{m}^{2}$, $y=28.6885$

$$
\begin{aligned}
& \mathrm{AT}=\mathrm{MT}-28.6885, \\
& \left(\text { at } 800 \mathrm{~W} / \mathrm{m}^{2},\right. \\
& \mathrm{MT}=59.61709) \\
& \mathrm{AT}=30.92^{\circ} \mathrm{C}
\end{aligned}
$$

From the above calculations, the AT for monocrystalline, polycrystalline and CIS thin film were $31.08^{\circ} \mathrm{C}, 31.15^{\circ} \mathrm{C}$ and $30.92^{\circ} \mathrm{C}$ respectively. These three values are obviously consistent within $31^{\circ} \mathrm{C}$. Thus, the proposed AT for SRE in NOCT testing at this stage of analysis is $31^{\circ} \mathrm{C}$ in relation to $800 \mathrm{~W} / \mathrm{m}^{2}$ of SI. These values of AT and SI are significantly different from the earlier finding of this study in section 3.2 that addressed the median values of AT of $30^{\circ} \mathrm{C}$ corresponding to SI of $228 \mathrm{~W} / \mathrm{m}^{2}$.

However, element of comparison is essential to verify the accuracy of the chosen AT and SI that will be used in the NOCT determination in tropical climate. The comparison will be made between the finding in section 3.2 designated as 'Revised1 $\left(\mathrm{AT}=30{ }^{\circ} \mathrm{C}\right.$ and $\left.\mathrm{SI}=228 \mathrm{~W} / \mathrm{m}^{2}\right)$ and the outcome of this recent finding designated as 'Revised $2^{\prime}\left(\mathrm{AT}=31^{\circ} \mathrm{C}\right.$ and $\left.\mathrm{SI}=800 \mathrm{~W} / \mathrm{m}^{2}\right)$. In order to do this, the NOCT of each finding and the percentage error (as compared to the actual measured data) will be determined in deriving to an accurate NOCT in tropical region.

The NOCT values were determined by data filtration of greater than $400 \mathrm{~W} / \mathrm{m}^{2}$ as aligned with NOCT testing Procedure 10.5.3 in international standard [3]. This is also to avoid errors due to PV module's thermal mass that might be attributed by clouds intermittent and other ambient fluctuation factors [6]. Based on Table 3, 4 and 5, the NOCT values for 'Revised1' of monocrystalline, polycrystalline and thin film were $41.9^{\circ} \mathrm{C}, 42.1^{\circ} \mathrm{C}$ and $44.4^{\circ} \mathrm{C}$ respectively. Meanwhile, the NOCT values for 'Revised $2^{\prime}$ of monocrystalline, polycrystalline and thin film were $53 .{ }^{\circ} \mathrm{C}, 54 .{ }^{\circ} \mathrm{C}$ and $58 .{ }^{\circ} \mathrm{C}$ correspondingly. In summary, the NOCT values for all the three technologies are significantly higher using 'Revised2' approach as compared to 'Revised1' approach. Subsequently, the percentage error improved by $21 \%$ to $23 \%$ for the three PV module technologies when 'Revised2' approach was implemented. Thus, the 'Revised2' SRE has much lower percentage error as compared to 'Revised1' SRE.

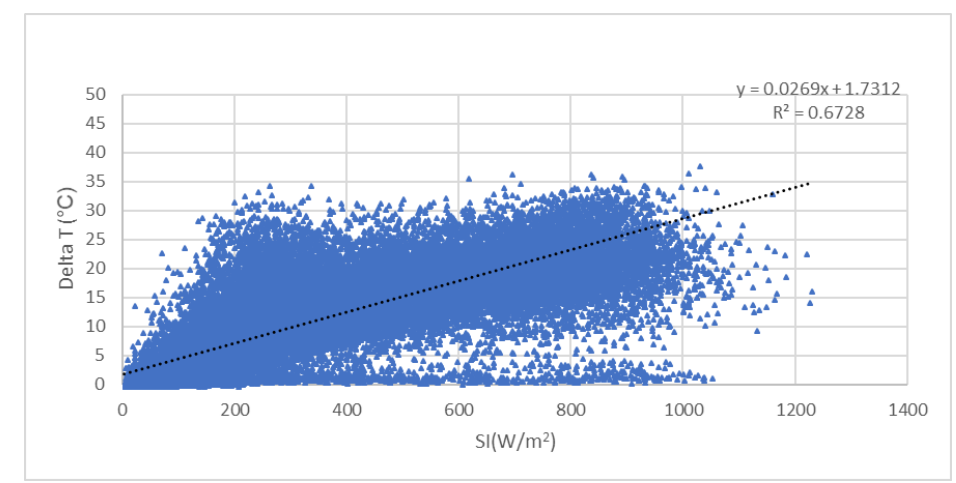

Figure 4. Delta T vs SI for Monocrystalline

The summary of the parameters for the present SRE as compared to proposed SRE (from this study) is shown in Table 6. From the five parameters, only two parameters were changed that are tilt angle and AT. The tilt angle follows local latitude of the chosen site and AT of $31^{\circ} \mathrm{C}$ as determined in this study [11]. 


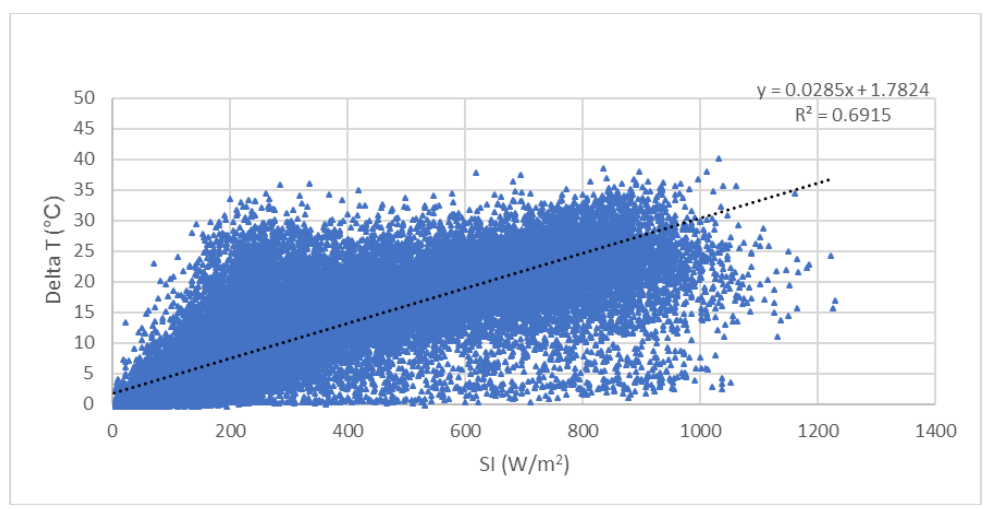

Figure 5. Delta T vs SI for Polycrystalline

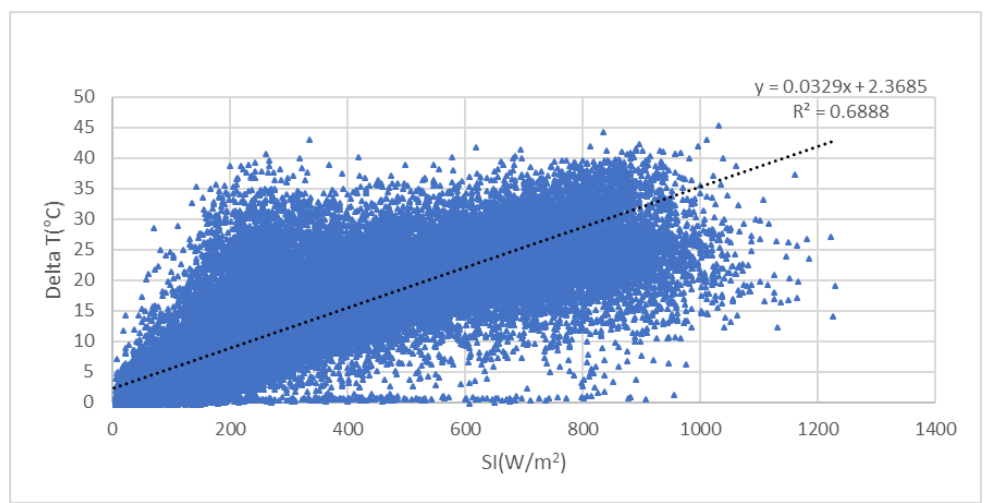

Figure 6. Delta T vs SI for Thin film

Table 3. SI SRE Point Test Summary (above $400 \mathrm{~W} / \mathrm{m}^{2}$ range) For Mono

\begin{tabular}{lll}
\hline Parameter & NOCT value $\left({ }^{\circ} \mathrm{C}\right)$ & Percentage error $(\%)$ \\
\hline $228 \mathrm{~W} / \mathrm{m}^{2}$ SI, $30^{\circ} \mathrm{C}$ AT (Revised 1) & 41.899 & 29.65 \\
$800 \mathrm{~W} / \mathrm{m}^{2}$ SI, 32 $2^{\circ} \mathrm{C}$ AT (Revised 2) & 53.345 & 8.92 \\
\hline
\end{tabular}

Table 4. SI SRE Point Test Summary (above $400 \mathrm{~W} / \mathrm{m}^{2}$ range) For Poly

\begin{tabular}{lll}
\hline Parameter & NOCT value $\left({ }^{\circ} \mathrm{C}\right)$ & Percentage error $(\%)$ \\
\hline $228 \mathrm{~W} / \mathrm{m}^{2}$ SI, $30^{\circ} \mathrm{C}$ AT (Revised 1) & 42.135 & 28.32 \\
$800 \mathrm{~W} / \mathrm{m}^{2}$ SI, $32^{\circ} \mathrm{C}$ AT (Revised 2) & 54.648 & 8.66 \\
\hline
\end{tabular}

Table 5. SI SRE Point Test Summary (above $400 \mathrm{~W} / \mathrm{m}^{2}$ range) For Thin Film

\begin{tabular}{lll}
\hline Parameter & NOCT value $\left({ }^{\circ} \mathrm{C}\right)$ & Percentage error $(\%)$ \\
\hline $228 \mathrm{~W} / \mathrm{m}^{2}$ SI, $30^{\circ} \mathrm{C}$ AT (Revised 1) & 44.412 & 32.20 \\
$800 \mathrm{~W} / \mathrm{m}^{2}$ SI, 32 $2^{\circ} \mathrm{C}$ AT (Revised 2) & 58.316 & 9.03 \\
\hline
\end{tabular}

Table 6. Comparison of Present SRE and Proposed SRE

\begin{tabular}{llll}
\hline Parameter & Present SRE & Proposed SRE & Remark \\
\hline Tilt Angle & $45^{\circ}$ & Local latitude & Changed \\
SI & $800 \mathrm{~W} / \mathrm{m}^{2}$ & $800 \mathrm{~W} / \mathrm{m}^{2}$ & Remain unchanged \\
AT & $20^{\circ} \mathrm{C}$ & $31{ }^{\circ} \mathrm{C}$ & Changed \\
WS & $1 \mathrm{~m} / \mathrm{s}$ & $1 \mathrm{~m} / \mathrm{s}$ & Remain unchanged \\
Electrical Load & Nil (Open circuit) & Nil (Open circuit) & Remain unchanged \\
\hline
\end{tabular}

\section{Conclusion}

In establishing the SRE ambient parameters for representing tropical climate region, a one-year statistical analysis and details monthly statistical analysis of five minutes data logging interval of SI, AT, RH, WS, WD and MT were determined. From the outcome of the statistical analysis, regression analysis and percentage error analysis executed using dedicated approach to suit tropical region; the revised ambient 
parameter of SRE was determined. The revised ambient parameter is only AT, which is $31{ }^{\circ} \mathrm{C}$ compared to current AT which is at $20^{\circ} \mathrm{C}$. This also means that the remaining two ambient parameters, which are SI and WS remain the same as stated in international standard. Therefore, the proposed ambient parameters of SRE for tropical region are SI of $800 \mathrm{~W} / \mathrm{m}^{2}$, AT of $31{ }^{\circ} \mathrm{C}$ and WS of $1 \mathrm{~m} / \mathrm{s}$. The new proposed AT rating of SRE for NOCT testing is significant to benefit all PV testing facilities in tropical region in deriving towards a more accurate NOCT values.

\section{Acknowledgement}

The authors express greatest gratitude to Universiti Teknologi MARA (UiTM) for funding this research under research grant of 600-IRMI/MyRA 5/3/BESTARI (017/2017).

\section{References}

[1] M. Kottek, J. Grieser, C. Beck, B. Rudolf, and F. Rubel, "World map of the Köppen-Geiger climate classification updated," Meteorol. Zeitschrift, vol. 15, no. 3, pp. 259-263, 2006.

[2] SEDA, "Seda Portal," SEDA Malaysia, 2017.

[3] IEC61215, Crystalline Silicon Terrestrial Photovoltaic (PV) Modules - Design Qualification and Type Approval (IEC 61215:2005,IDT). Malaysia, Deparment Of Standards, 2006.

[4] IEC61646, Thin-film Terrestrial Photovoltaic (PV) Modules Design -Qualification and Type Approval. (First Revision)(IEC 61646:2008,IDT). Malaysia, Deparment Of Standards, 2010.

[5] A. Mohamed and T. Khatib, "Correlation for estimating solar cell temperature based on a tropical field operation of a photovoltaic system,” 2014 IEEE PES T\&D Conf. Expo., pp. 1-5, 2014.

[6] M. Koehl, M. Heck, S. Wiesmeier, and J. Wirth, "Modeling of the nominal operating cell temperature based on outdoor weathering," Sol. Energy Mater. Sol. Cells, vol. 95, no. 7, pp. 1638-1646, 2011.

[7] M. M. M. Hanifah, Zainuddin, and M. Z. Hussin, "Evaluation of standard reference environment for photovoltaic nominal operating cell temperature testing in Malaysia," Indones. J. Electr. Eng. Comput. Sci., vol. 8, no. 1, pp. 245-252, 2017.

[8] J. W.Stultz, "Thermal \& Other Tests of Photovoltaic modules performed in natural sunlight." 1979.

[9] Z. Ye, A. Nobre, T. Reindl, J. Luther, and C. Reise, "On PV module temperatures in tropical regions," Sol. Energy, vol. 88, pp. 80-87, 2013.

[10] J. Y. Ye, K. Ding, T. Reindl, and A. G. Aberle, "Outdoor PV module performance under fluctuating irradiance conditions in tropical climates," Energy Procedia, vol. 33, pp. 238-247, 2013.

[11] M. Z. Jacobson and V. Jadhav, "World estimates of PV optimal tilt angles and ratios of sunlight incident upon tilted and tracked PV panels relative to horizontal panels," Sol. Energy, vol. 169, no. December 2017, pp. 55-66, 2018.

[12] IEC61853-1, International Standard: Photovoltaic (PV) module performance testing and energy rating - Part 1: Irradiance and temperature performance measurements and power rating, no. April. 2011.

[13] J. W.Stultz, "Thermal and Other Tests of Photovoltaic Modules Performed in Natural Sunlight," 1978. 